\title{
Heterogeneous reduction of nitric oxide on synthetic coal chars
}

\author{
C. Pevida, A. Arenillas, F. Rubiera, J.J. Pis* \\ Instituto Nacional del Carbón, CSIC. Apartado 73. 33080 Oviedo, Spain.
}

\begin{abstract}
Model compounds, with a controlled heteroatoms content and well-defined functionalities, were used to study the release of nitrogen compounds from char combustion. In the present work, the mechanisms involved in NO-char heterogeneous reduction were studied with a synthetic coal (SC) char as carbon source. Another synthetic char (SN) without any nitrogen in its composition was also employed in these studies. Temperature programmed reduction (TPR) tests with a gas mixture of $400 \mathrm{ppm}$ NO in argon and with isotopically labelled nitric oxide, ${ }^{15} \mathrm{NO}$ (500 ppm ${ }^{15} \mathrm{NO}$ in argon), were carried out. The gases produced were quantitatively determined by means of MS and FTIR analysers.

Under the conditions of this work the main products of the NO-C reaction were found to be $\mathrm{N}_{2}$ and $\mathrm{CO}_{2}$. The main path of reaction involves the formation of surface nitrogen compounds that afterwards react with nitrogen from the reactive gas to form $\mathrm{N}_{2}$. It was observed that fuel-N also participates in the overall heterogeneous reduction reaction, although to a lesser extent.
\end{abstract}

Keywords: NOx, heterogeneous reduction, coal char, model compounds

\section{INTRODUCTION}

The emission of nitrogen oxides from coal combustion poses one of the greatest challenges in the field of environmental protection. It is well known that NO is one of the main contributors to acid rain and $\mathrm{N}_{2} \mathrm{O}$ is a greenhouse gas, which indirectly depletes the ozone layer [1]. Char nitrogen is the main source of NOx in both fluidised bed coal combustion and when low NOx burners are used for pulverised fuel 
combustion [2,3]. For this reason, the minimisation of NOx emissions from char is currently a research topic of great interest.

The reduction of NO by char is an important reaction that determines the conversion of fuel-N to NO during coal combustion. The heterogeneous NO-coal char reaction is quite complex, involving several processes (e.g. chemisorption, the desorption of surface complexes, and the release of products during gasification) that are still not fully understood. In addition, coal has a very complex and heterogeneous structure which makes it even more difficult to isolate the factors that influence NOx release during combustion. The chemistry involved in NOx formation and the reduction reactions has already been studied but a deeper knowledge of these reactions is still required $[4,5,6]$. The use of single model compounds, with a controlled heteroatom content and welldefined functionalities, is a method that has been employed by many authors to study the release of nitrogen compounds from char combustion $[7,8]$. However, this approach does not take into account important aspects such as coal structure and the interactions between different surface groups.

In the present work a synthetic coal (SC) was used as carbon source in the NO-char heterogeneous reduction studies. This synthetic coal was made by mixing and curing a series of model compounds (phenol-formaldehyde resin, PFR, perilentetracarboxilicacid-dianhydride, PTC) and by incorporating nitrogen functionalities commonly present in coal (polyvinylpyrrolidone, PVP, and poly-4-vinylpyridine, p4VP). The preparation and thermal stabilisation of the mixture has been described elsewhere [9]. The formation of cross-linkages between the model compounds led to a unique carbon structure that is referred to as synthetic coal (SC). The behaviour of this sample, SC, resembles reasonably well that of a high volatile bituminous coal [9-12]. The absence of 
mineral matter in the mixture prevents possible catalytic effects, which are undesirable when trying to isolate the effect of carbon active surface groups.

The use of this carbon source with controlled and known composition as a well substitute for coal chars, the possibility of obtaining a carbonaceous material with the same structure but without nitrogen in its composition besides the use of NO and isotopically labelled ${ }^{15} \mathrm{NO}$ as reactive gas in the TPR experiments leads to new and relevant data still not reported by the groups with a solid expertise in the area. The results presented in this work are part of a broader study on the heterogeneous reduction of nitrogen oxides on carbonaceous materials.

\section{METHOD}

The study of the NO-C reaction was carried out on a char produced from the pyrolysis of the synthetic coal (SC char). The pyrolysis was carried out in a horizontal quartz reactor (i.d. $30 \mathrm{~mm}$ ), under He flow, at a heating rate of $15^{\circ} \mathrm{C} \mathrm{min}^{-1}$ up to a maximum temperature of $850^{\circ} \mathrm{C}$. Another synthetic char (SN char) without any nitrogen in its composition was also employed in these studies. The SN char was obtained from a mixture of PFR and PTC as carbon precursors. Another char, obtained from the pyrolysis of a high volatile bituminous coal (CA char), was also used for comparative purposes.

A thermogravimetric analyser (Setaram TGA 92) linked to a gas analysis system, MS (Balzers MSC 200) and FTIR (Nicolet Nexus, DTGS detector and $\mathrm{KBr}$ windows) mounted in parallel, was used to study the evolution of gaseous compounds during the experiments. 
The chars were subjected to different temperature programmed reduction (TPR) tests using gas mixtures of $400 \mathrm{ppm} \mathrm{NO}$ and $500 \mathrm{ppm}$ of ${ }^{15} \mathrm{NO}$ (isotopically labelled) in argon. The use of isotopically labelled nitric oxide makes it possible to distinguish between the role of the nitrogen contained in the char composition and the nitrogen that originates from the gas phase (i.e., reactive NO). Moreover, by employing SC char and SN char, which have a well controlled and well known composition, it is possible to study the influence that the presence or absence of nitrogen in the char composition has on the NO heterogeneous reduction reaction. At the same time, the influence of the type and concentration of reactive sites was studied by means of temperature programmed desorption tests (TPD).

In a typical experiment $2 \mathrm{mg}$ of sample was placed in the thermobalance crucible. The tests were performed at a heating rate of $15^{\circ} \mathrm{C} \min ^{-1}$ up to $1000^{\circ} \mathrm{C}$ under a $50 \mathrm{ml} \mathrm{min}{ }^{-1}$ flow rate of the corresponding reactive gas mixture: $\mathrm{NO},{ }^{15} \mathrm{NO}$, or $\mathrm{Ar}$ in the case of the TPD tests.

For the quantitative gas analysis it was necessary to devise an experimental procedure using gas mixtures of a known composition as calibration standards: $\mathrm{CO}, \mathrm{CO}_{2}, \mathrm{~N}_{2}, \mathrm{NO}$ and $\mathrm{N}_{2} \mathrm{O}$ in Argon. A series of $\mathrm{m} / \mathrm{z}$ assignments for the $\mathrm{MS}$ and appropriate infrared absorption bands for the FTIR analysis were selected [10].

\section{RESULTS AND DISCUSSION}

The proximate and ultimate analyses of the chars are shown in Table 1 . The volatile matter, carbon and hydrogen contents were very similar for the three chars, the main difference being the absence of mineral matter and sulphur in the synthetic chars. However, it should be noted that the oxygen content of the SN char was higher than that 
of the other two chars. A thorough characterisation of the chars was performed, as described elsewhere [9-12].

TPR tests were carried out in order to study the reaction profiles of the heterogeneous NO reduction. These tests provide valuable information about the main gaseous species formed and about the stages through which heterogeneous NO reduction proceeds. Figure 1 shows the NO reduction profiles, analysed by MS and FTIR, during the TPR tests with 400 ppm NO in Ar for the three chars (SC, SN and CA chars). On comparing the NO reduction profiles obtained by MS and FTIR, it can be observed that the gaseous compounds analysis system is perfectly synchronised and that both techniques give analogous concentration values.

The presence of the char reduces the NO concentration efficiently, with a maximum reduction of nearly $80 \%$. In the very early stages of the experiments, at low temperatures, NO reduction is not significant. At around $300^{\circ} \mathrm{C}$ there is a slight increase in NO reduction that is attributed to the well-known chemisorption of $\mathrm{NO}$ on the carbon surface at temperatures above ambient [13]. The C-NO reaction did not start until $600^{\circ} \mathrm{C}, \mathrm{CO}_{2}$ and $\mathrm{N}_{2}$ being the main reduction products. Under the experimental conditions used in this work in the TPR tests neither $\mathrm{CO}$ nor $\mathrm{N}_{2} \mathrm{O}$, as described by other authors [14,15], were detected. The evolutions of $\mathrm{N}_{2}$ and $\mathrm{CO}_{2}$ are shown in Figure 2. $\mathrm{N}_{2}$ is undoubtedly a reduction product, as can be inferred from the similarities between the $\mathrm{N}_{2}$ profiles of the synthetic char with nitrogen (i.e. SC char) and without nitrogen (i.e. SN char) in their composition, and also from the NO reduction profiles shown in Figure 1. However, the emission of $\mathrm{CO}_{2}$ starts at lower temperatures, indicating that there is a contribution from the oxygen groups inherent to the chars in addition to the $\mathrm{CO}_{2}$ formed as a reduction reaction product. 
The small differences observed in the reduction of $\mathrm{NO}$ and in the $\mathrm{N}_{2}$ profiles for the synthetic chars (i.e. SC and SN chars) is possibly due to the slight influence of the fuel nitrogen on the heterogeneous NO reduction.

For the CA char the results are in good agreement with those of the synthetic chars. Thus, they provide a valid representation for the study of NO reduction on real carbonaceous materials. These results corroborate previous works [11] which showed analogous NO formations in temperature programmed combustion tests for CA and SC. In this way, the usefulness of synthetic coal and its char for the study of the heterogeneous formation/reduction reactions of nitrogen oxides is confirmed.

In order to study the influence of the type and concentration of the active surface sites on the NO heterogeneous reduction, TPD tests under Ar flow were carried out. This thermal treatment allows the release of oxygen surface groups which then evolve as carbon monoxide and carbon dioxide. $\mathrm{CO}$ and $\mathrm{CO}_{2}$ profiles for the TPD tests of the chars are shown in Figure 3. The evolution of $\mathrm{CO}_{2}$ is assigned to the decomposition of carboxylic and anhydride groups. The three chars have a similar behaviour. They do not display any characteristic temperature and $\mathrm{CO}_{2}$ is detected throughout the temperature range. However, the chars do present differences in CO evolution. While for the SC and CA chars the $\mathrm{CO}$ desorption peaks show a maximum at around $1000^{\circ} \mathrm{C}$, for $\mathrm{SN}$ the peak shifts to lower temperatures (around $850^{\circ} \mathrm{C}$ ) with a shoulder at $1000^{\circ} \mathrm{C}$. This suggests a different distribution of the groups responsible for such emissions. Carbonyl, ether and quinone groups evolve as CO, but they decompose at different temperatures [16]. Thus, in the light of the results obtained, SN char could have a higher amount of carbonyl and ether groups, whereas the SC and CA chars contain mainly quinone groups. 
After the TPD experiments the chars, devoid of surface oxygen labile groups, were subjected to TPR tests under 400 ppm NO in Ar. Figure 4 shows the NO reduction profiles obtained for the three chars during the TPR tests after the heat treatment. The peak at the low temperature, assigned to NO chemisorption in Figure 1, has disappeared, pointing to the influence of surface oxygen compounds on the chemisorption step. There is a marked decrease in NO maximum reduction from $80 \%$ when no thermal pre-treatment was applied (Figure 1), to $30 \%$ when the chars were heat-treated before the TPR tests. It would seem, therefore, that oxygen surface compounds play a determining role in NO heterogeneous reduction, influencing the chemisorption step at lower temperatures and, consequently, the NO-C gasification reaction at higher temperatures.

The synthetic chars behave in a similar manner showing a maximum NO reduction at $1000^{\circ} \mathrm{C}$, as was expected. For the CA char maximum NO reduction is obtained at around $850^{\circ} \mathrm{C} . \mathrm{N}_{2}$ and $\mathrm{CO}_{2}$ were once again the main reduction products detected in all the experiments.

TPR tests using isotopically labelled nitric oxide $\left({ }^{15} \mathrm{NO}\right)$ were also carried out. In this way it was possible to establish the source of the nitrogen that formed $\mathrm{N}_{2}$ as a reduction product, because ${ }^{14} \mathrm{~N}$ comes from the chars (CA and SC chars) and ${ }^{15} \mathrm{~N}$ comes from the nitrogen contained in the reactive gas. In these tests special attention was paid to the nitrogenous reduction products.

Figure 5 shows the profiles of the reduction products obtained during the TPR tests using isotopically labelled nitric oxide. The gas analysis was performed by MS in order to distinguish between ${ }^{14} \mathrm{~N}_{2}(\mathrm{~m} / \mathrm{z} 28),{ }^{14} \mathrm{~N}^{15} \mathrm{~N}(\mathrm{~m} / \mathrm{z} 29)$ and ${ }^{15} \mathrm{~N}_{2}(\mathrm{~m} / \mathrm{z} 30)$. Quantitative 
analysis was only possible for $\mathrm{CO}_{2}$ as calibration standards were not available for the other compounds.

The evolution of $\mathrm{CO}_{2}$ was similar to that observed during the TPR tests with nonisotopic nitric oxide (see Figure 2), although lower concentrations were obtained for the SC char. There was no ${ }^{14} \mathrm{~N}_{2}$ in the experiments with isotopic nitric oxide which suggests that the possibility of a reaction between nitrogen atoms in the char composition (i.e. CA and SC chars) is low.

The analysis of signal $\mathrm{m} / \mathrm{z} 30$, assigned to ${ }^{15} \mathrm{~N}_{2}$ in these experiments, shows similar profiles for the three chars, with maxima centred at around $1000{ }^{\circ} \mathrm{C} .{ }^{15} \mathrm{~N}_{2}$ is the main nitrogenous reduction product in the TPR tests with isotopic nitric oxide, suggesting that the main path of reaction starts with the formation of surface nitrogen compounds that then react with the nitrogen from the reactive gas.

However, by using a carbonaceous material without any $\mathrm{N}$ in its composition, SN char, and isotopically labelled NO, it was proved that there is another NO heterogeneous reduction pathway in addition to the main one. The profiles corresponding to signal $\mathrm{m} / \mathrm{z}$ 29, assigned to ${ }^{14} \mathrm{~N}^{15} \mathrm{~N}$ in these tests, present maxima near $1000^{\circ} \mathrm{C}$ for the SC and CA chars, which is indicative of a reaction between the nitrogen, ${ }^{14} \mathrm{~N}$, in the chars (the socalled fuel nitrogen) and the nitrogen, ${ }^{15} \mathrm{~N}$, from the reactive gas. The $\mathrm{SN}$ char does not show any peak for $\mathrm{m} / \mathrm{z} 29$, due to the absence of nitrogen in its composition.

\section{CONCLUSIONS}

The similarities observed between the synthetic chars (i.e. SC and SN chars) and the coal char (i.e. CA char) validate the study of NO heterogeneous reduction, using synthetic chars as carbonaceous materials. 
In the experimental conditions of the present work, NO heterogeneous reduction over the char surface (synthetic and non synthetic) generated $\mathrm{N}_{2}$ and $\mathrm{CO}_{2}$ as reduction products. Neither $\mathrm{CO}$ nor $\mathrm{N}_{2} \mathrm{O}$, as described by other authors, were detected.

The presence of oxygen surface compounds determines NO chemisorption on the char surface and this influences the NO-C gasification reaction at higher temperatures.

The behaviour observed for the chars with nitrogen and without nitrogen was very similar in all the reduction experiments. However, the use of isotopically labelled NO and synthetic chars with a well controlled composition revealed that the nitrogen already present in the chars (CA and SC chars) also participates, although to a lesser extent, in the NO heterogeneous reduction process.

\section{REFERENCES}

[1] Sloss LL. IEACR/36, IEA Coal Research 1991.

[2] Jones JM, Thomas KM. Carbon 1995; 33:1129.

[3] Thomas KM. Fuel 1997; 76:457.

[4] Teng H, Suuberg EM. Industrial and Engineering Chemistry Research 1993; 32:416.

[5] Chambrion P, Suzuki T, Zhang ZG, Kyotani T, Tomita A. Energy and Fuels 1997; 11:681.

[6] Tomita A. Fuel Processing Technology 2001; 71:53.

[7] Pels JR. PhD Thesis, University of Delft 1995.

[8] Schmiers H, Friebel J, Streubel P, Hesse R, Köpsel R. Carbon 1999; 37:1965. 
[9] Arenillas A, Pevida C, Rubiera F, García R, Pis JJ. Journal of Analytical and Applied Pyrolysis 2004; 71:747.

[10] Pevida C. PhD Thesis, University of Oviedo 2004.

[11] Arenillas A, Pevida C, Rubiera F, Pis JJ. Fuel 2003; 82:2001.

[12] Arenillas A, Pevida C, Rubiera F, Palacios JM, Navarrete R, Denoyel R, Rouquerol J, Pis JJ. Carbon 2004; 42:1345.

[13] Aarna I, Suuberg EM. Fuel 1997; 78:475.

[14] Teng H, Suuberg EM, Calo JM. Energy and Fuels 1992; 6:398.

[15] Chambrion P, Kyotani T, Tomita A. Energy and Fuels 1998; 12:416.

[16] Figueiredo JL, Pereira MFR., Freitas MMA., Orfao JJM. Carbon 1999; 37:1379. 
Table 1 Proximate and ultimate analyses of the chars

\begin{tabular}{|c|c|c|c|c|c|c|c|}
\hline & \multicolumn{2}{|c|}{ Proximate analysis (wt\%, db) } & \multicolumn{5}{|c|}{ Ultimate analysis (wt\%, daf) } \\
\hline & $\begin{array}{c}\text { Volatile } \\
\text { matter }\end{array}$ & Ash & $\mathrm{C}$ & $\mathrm{H}$ & $\mathrm{N}$ & S & $\mathrm{O}$ \\
\hline SC char & 11.3 & - & 95.5 & 1.2 & 1.6 & - & 1.7 \\
\hline SN char & 9.8 & - & 94.7 & 1.5 & - & - & 3.8 \\
\hline CA char & 7.9 & 14.0 & 93.0 & 1.3 & 2.1 & 2.1 & 1.5 \\
\hline
\end{tabular}




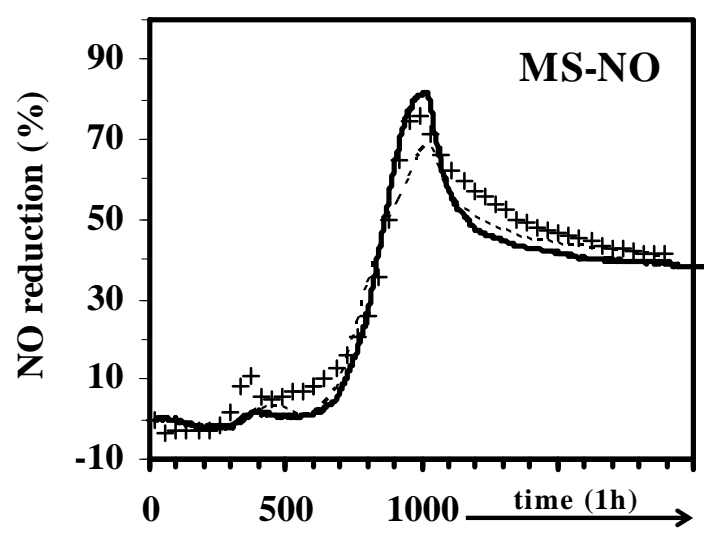

Temperature $\left({ }^{\circ} \mathrm{C}\right)$

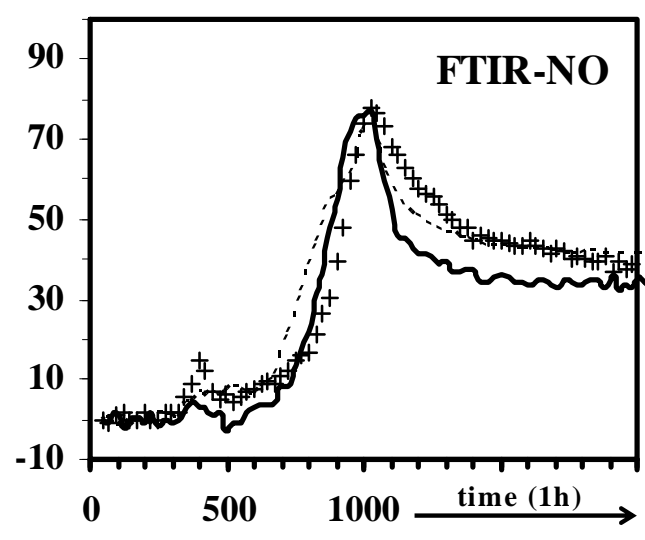

Temperature $\left({ }^{\circ} \mathrm{C}\right)$

$$
\text { + SC char - - SN char - CA char }
$$

Figure 1. NO reduction during the TPR tests for the CA, SC and SN chars. 


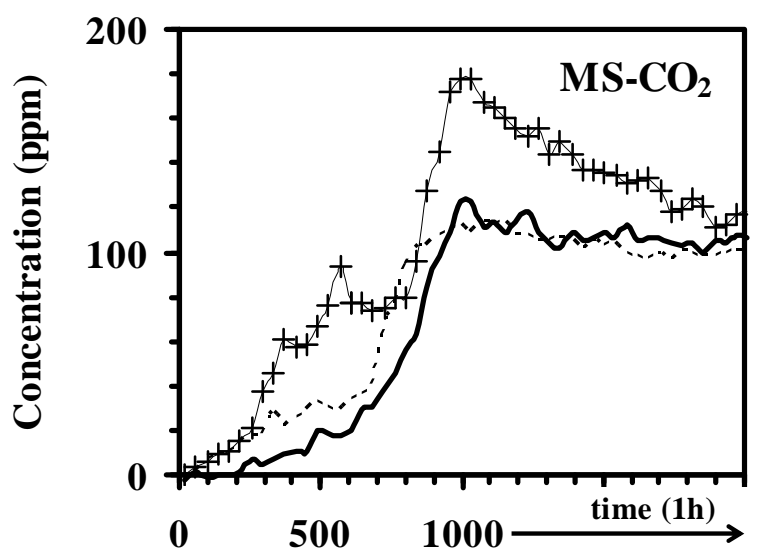

Temperature $\left({ }^{\circ} \mathrm{C}\right)$

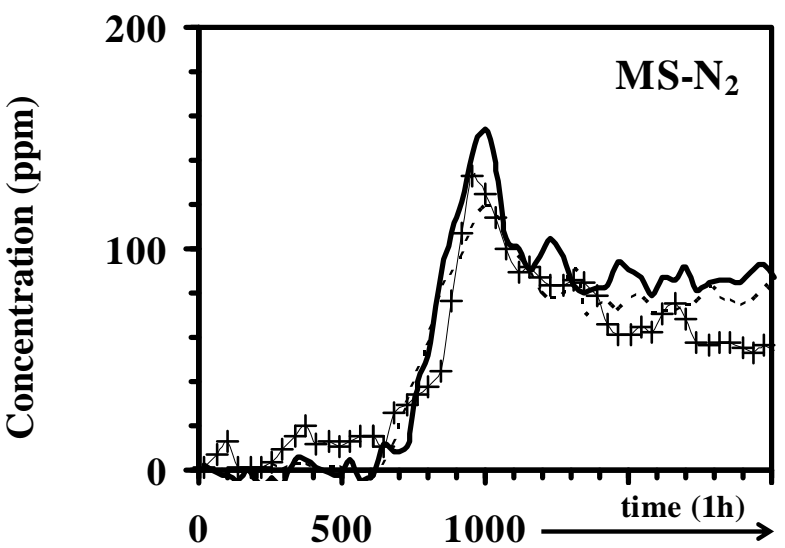

Temperature $\left({ }^{\circ} \mathrm{C}\right)$

$$
\text { + SC char - - SN char - CA char }
$$

Figure 2. $\mathrm{N}_{2}$ and $\mathrm{CO}_{2}$ evolution during the TPR tests for the CA, SC and SN chars. 


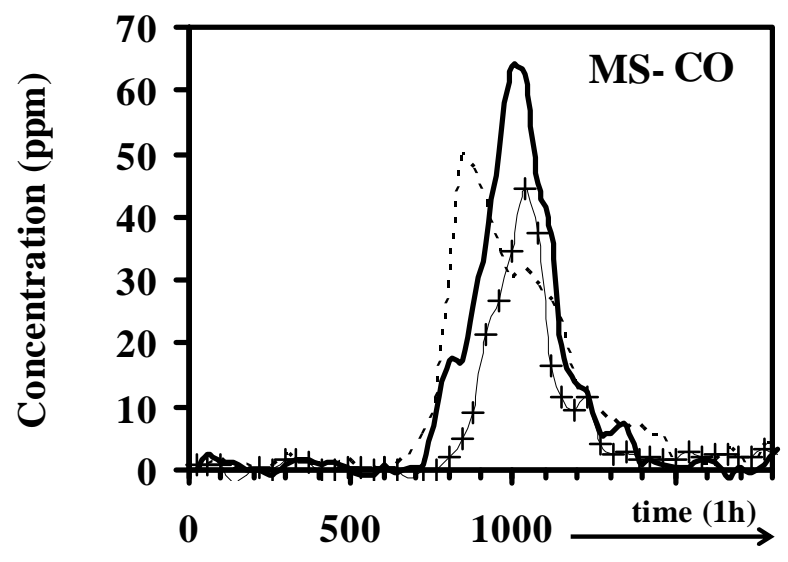

Temperature $\left({ }^{\circ} \mathrm{C}\right)$

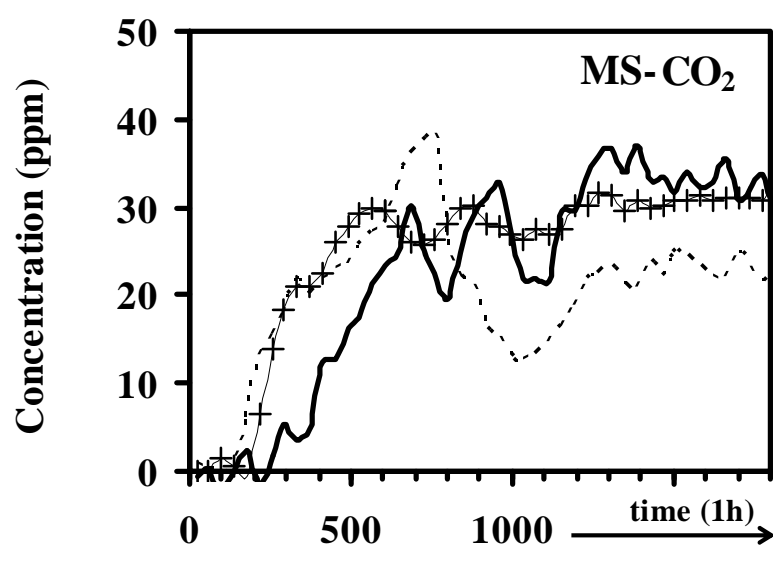

Temperature $\left({ }^{\circ} \mathrm{C}\right)$

+ SC char - - SN char - CA char

Figure 3. $\mathrm{CO}$ and $\mathrm{CO}_{2}$ evolution during the TPD tests for the CA, SC and SN chars. 


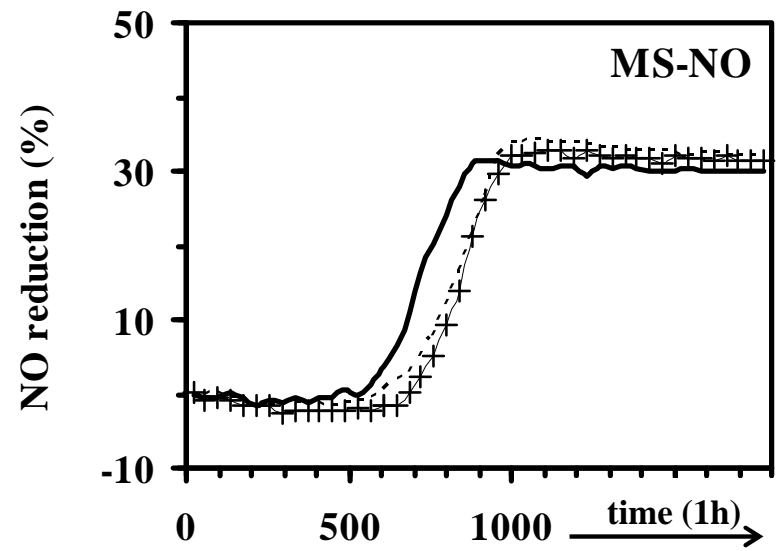

Temperature $\left({ }^{\circ} \mathrm{C}\right)$

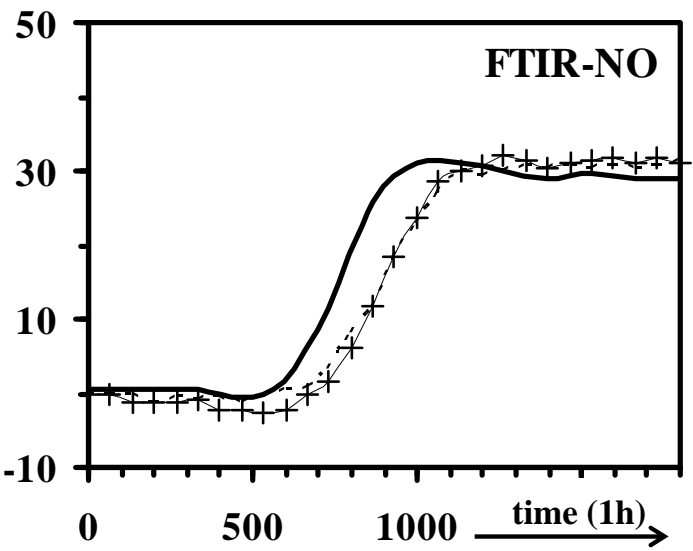

Temperature $\left({ }^{\circ} \mathrm{C}\right)$

$$
\text { + SC char --- SN char - CA char }
$$

Figure 4. NO reduction during the TPR tests after heat treatment for the CA, SC and SN chars. 


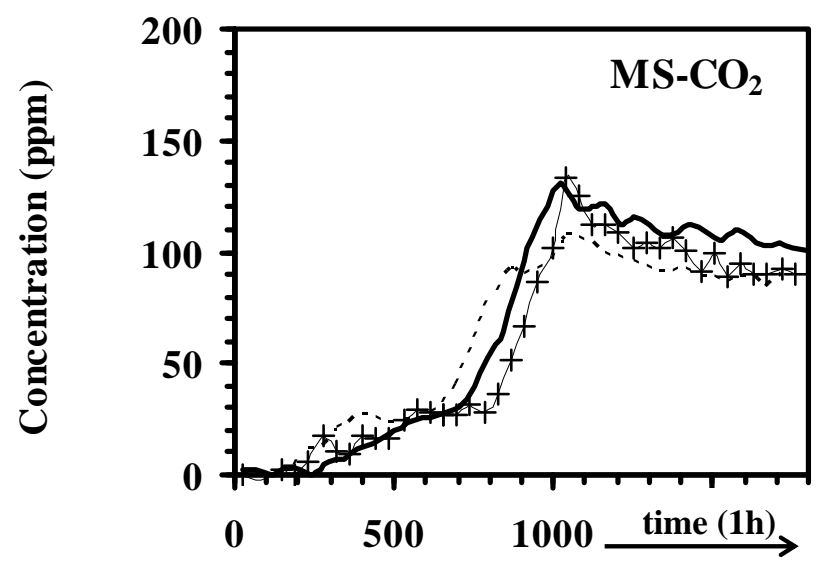

Temperature $\left({ }^{\circ} \mathrm{C}\right)$
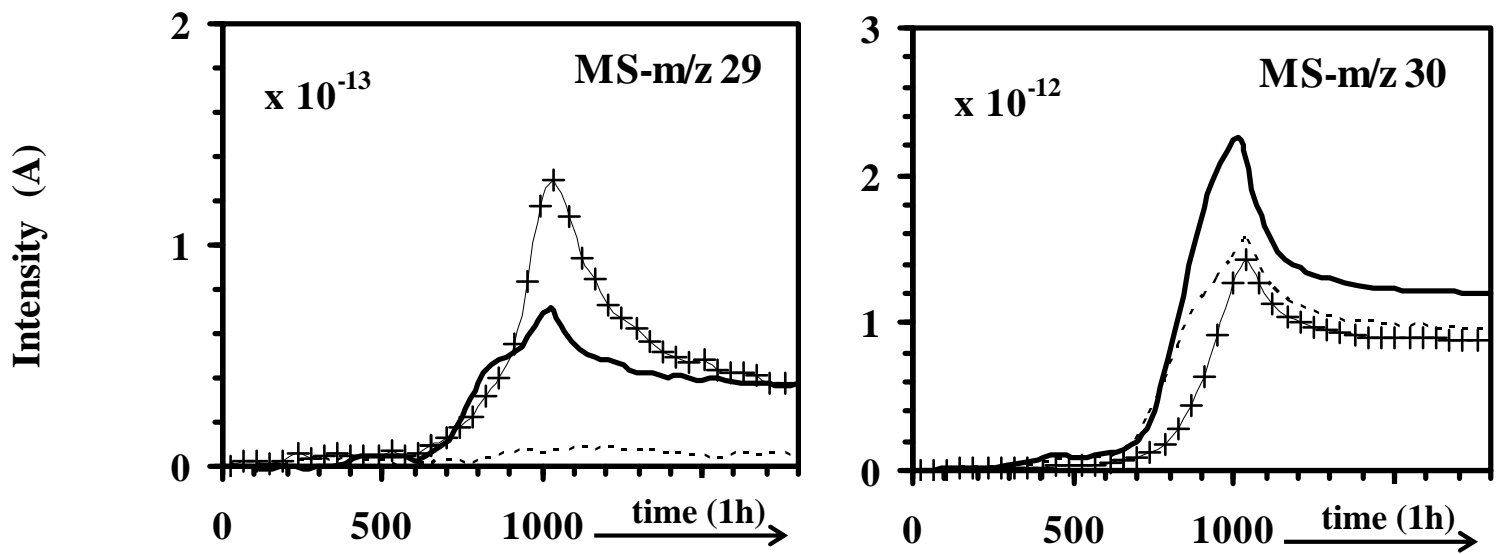

Temperature $\left({ }^{\circ} \mathrm{C}\right)$

Temperature $\left({ }^{\circ} \mathrm{C}\right)$

$$
\text { + SC char -. SN char - CA char }
$$

Figure 5. $\mathrm{CO}_{2},{ }^{14} \mathrm{~N}^{15} \mathrm{~N}\left(\mathrm{~m} / \mathrm{z}\right.$ 29) and ${ }^{15} \mathrm{~N}_{2}(\mathrm{~m} / \mathrm{z} 30)$ evolution during the TPR tests with ${ }^{15} \mathrm{NO}$ for the CA, SC and SN chars. 